\title{
Bilateral Semi Precision Removable Partial Denture Using Ceka Preci-Sagix Attachment System
}

Pratibha Marya ${ }^{1}$, Mohit Handa²

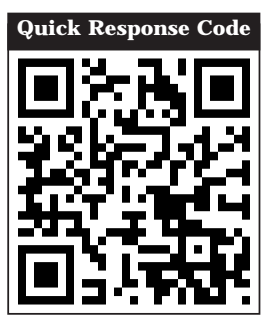

doi: $10.5866 / 2016.8 .10267$

1Private Practioner,

Ferozepur

2Senior Lecturer,

Department of Prosthodontics,

Dharshan Dental College,

Udaipur, Rajasthan

\section{Article Info:}

Received: October 09, 2016

Review Completed: November 10, 2016

Accepted: December 08, 2016

Available Online: December, 2016 (www.nacd.in)

(c) NAD, 2016 - All rights reserved

Email for correspondence:

dr.mohithanda@gmail.com

\begin{abstract}
:
Semi precision attachment removable partial dentures are the treatment modalities that can facilitate both esthetic and functional replacement of missing teeth and oral structures. They offer patients improved self-confidenceand self-image. The attachment requires adequate space and the correct angulation relative to the path of insertion of the denture. They are more stable and retentive than conventional dentures and for these reasons are better tolerated. The present article represents the use of a Semi-precision, extra-coronal attachment in a Kennedy Class I situation in removable partial denture.
\end{abstract}

Key words: Semi precision, Retention, Matrix, Patrix

\section{Introduction}

Loss of teeth causes an adverse effect not only on the functional and esthetic efficacy, but also has a big impact on the person's psychological well-being. The reduction in partial edentulism that has occurred in these days by successful preventive procedures and use of osseo-integrated implants has reduced the need for removable partial dentures. However, for a variety of reasons, many patients who have partial edentulism can continue to benefit from partial denture therapy; and these patients deserve increased retention with the best esthetic result possible in prosthesis. Important principles of design are good retention, stability and the denture which hamper natural cleaning and daily oral hygiene as little as possible. ${ }^{1}$ The primary esthetic objection to removable partial denture therapy is the unsightly display of the clasp assemblies. ${ }^{2}$ 
There are two types of pre-fabricated attachments. Precision attachment in which both the matrix and patrix parts of the attachment are delivered in ready to install forms and Semi Precision attachment in which a unit requires a casting procedure to beincorporated in the fixed part of restoration. Semi-precision attachments maximize stability and retention of the partially edentulous arch and are a simple, predictable, costeffective al ternative that is satisfying to the patient. Crowns on natural teeth may improve the fit of a RPD, and they are usually required for attachments. Semi-precision attachments are generally more esthetic than metal clasps, and they are nearly invisible. ${ }^{3}$ The present article represents the use of a Semi-precision, extra-coronal attachment in a Kennedy Class I situation in removable partial denture.

\section{Case Report}

A 65 year old female patient reported to the Department of Prosthetic Dentistry complaining of missing teeth and wants esthetic replacement with good retention and stability. Intraoral examination reveals Kennedy Class I edentulism in maxillary arch and Class II Div2 in mandibular arch with deep undercut in retro-mylohyoid region (Figure 1). She was wearing flexible removable partial denture in mandibular arch and was satisfied. After clinical and radiographic examination of patient semiprecision attachment cast partial denture in maxillary arch was planned as follows:

1. A diagnostic impression was made with irreversible hydrocolloid impression material and poured in dental stone to obtain the diagnostic cast.

2. Placement of two $2.2 \mathrm{~mm}$ Ceka Preci-Sagix attachment were planned on distal surfaces of 13 and 25.

3. Full veneer preparations were undertaken on $12,13,24,25$ and impression was made with additional siliconeimpression material and was poured in die stone to get the master cast.

4. 2 layers of die spacer were applied over it. Wax patterns were fabricated by dip wax technique,
2 patrix were attached to the distal surface of wax pattern on 13 and 25.

5. A paralleling mandrel was attached with surveyor for the correct position of patrix placement in wax patterns (Figure 2).

6. The wax pattern was sprued, casted with high noble metal alloy and finished with the conventional manner and ceramic application was done.

7. Crowns were checked in mouth for proper placement (Figure 3) and another impression was made along with crowns in the mouth with additional silicon material and poured in die stone.

8. Duplicating dummies of matrix part of attachment were placed over the patrix part on crowns with parallel alignment on the cast.

9. Cast was duplicated with Agar-Agar and wax pattern with a bracing arm on 13 and 25 was prepared over it (Figure 4).

10. Casting, finishing and polishing was done with the conventional manner without damaging the retentive ledge in the female part.

11. Full veneer crowns were cemented on the teeth and framework trial was done over them (Figure 5).

12. Maxillo-mandibular relationship, teeth arrangement and processing were done in conventional manner.

13. After processing, placement of matrix part of attachment which was having the same size as the duplicating dummy matrix attachment was inserted within the denture with insertion tool provided in the kit (Figure 6 and 7).

14. Recall visits were made at one week, one month and every six month interval and regular oral hygiene instructions were explained to the patient.

15. Patient was having phonetics problem so anterior strap from the denture was removed after one month. 


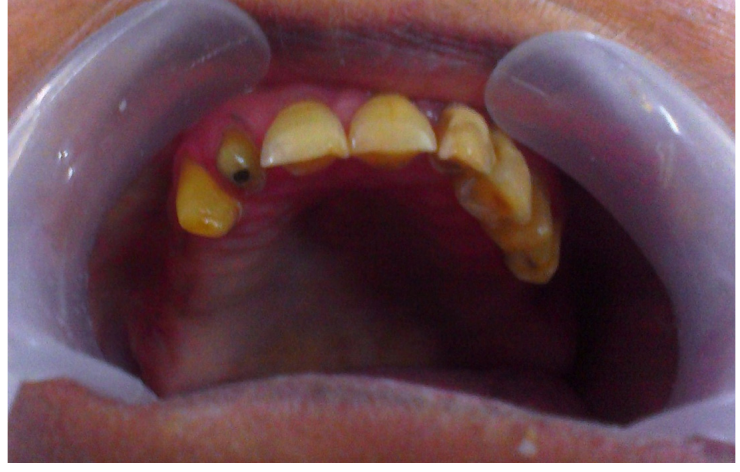

Figure 1: Intraoral examination reveals Kennedy Class I edentulism in maxillary arch.

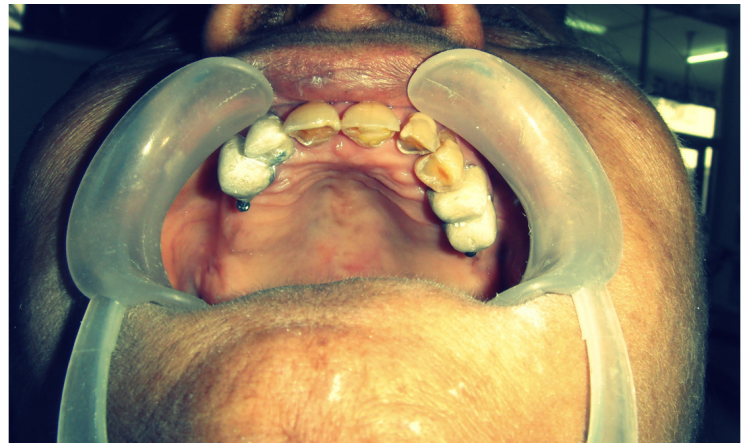

Figure 3: Checking of crowns in mouth for proper placement

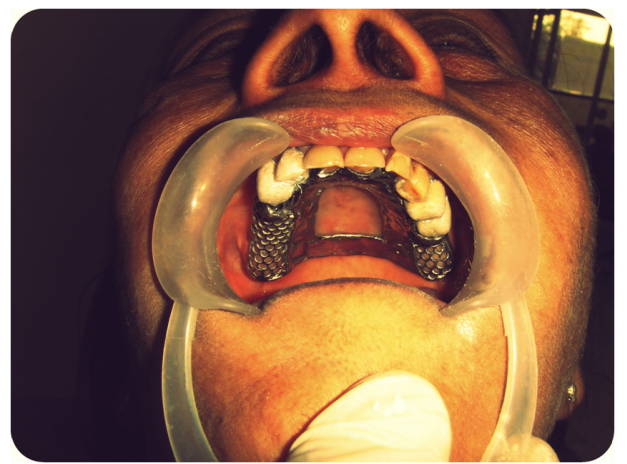

Figure 5: Full veneer crowns were cemented on the teeth and framework trial was done over them

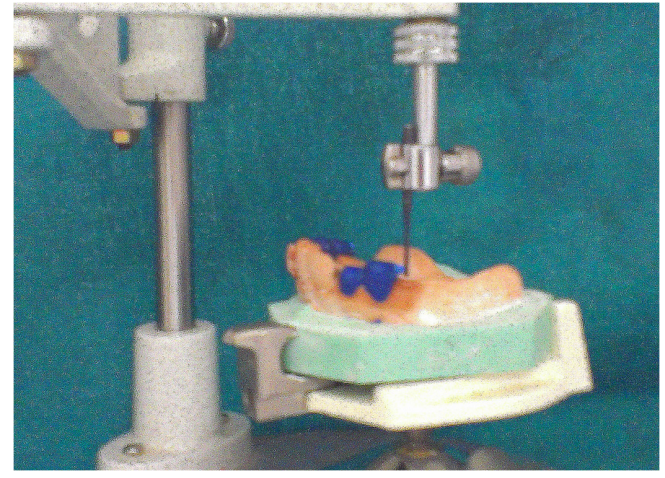

Figure 2: Attachment of paralleling mandrel with surveyor for the correct position of patrix placement in wax patterns.

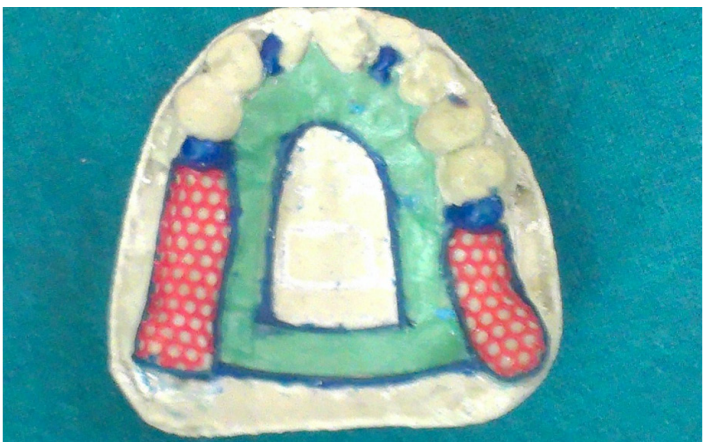

Figure 4: Cast was duplicated with Agar-Agar and wax pattern with a bracing arm on 13 and 25 was prepared over it

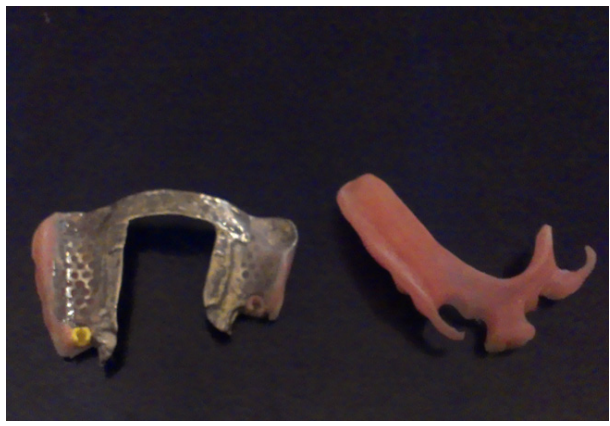

Figure 6: Placement of matrix part of attachment which was having the same size as the duplicating dummy matrix attachment was inserted within the denture

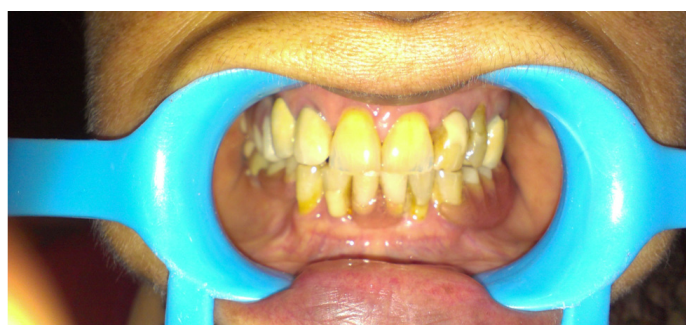

Figure 7: Post insertion picture showing replacement of teeth. 


\section{Discussion}

The prognosis of Ceka Preci Sagix attachment system is excellent because of its rigidity of support mechanism and design. It is available in 2 different patrix ball sizes $(1.7 \mathrm{~mm}$ and $2.2 \mathrm{~mm})$. The choice can be made depending upon inter-occlusal distance. The matrix components are available in different retention modes for better patient tolerance (yellow for normal retention, red for increased retention and white for reduced retention).

Semi precision partial dentures are retained in the mouth by means of mechanical interlocking components. The retentive mechanism is based on plastic female component that sits in a metal housing which fit snuggly to the male part attached with the crowns. ${ }^{4-6}$ The ball and socket type of attachment is seen to be user friendly for the patients. The snap fit of the denture in mouth also makes the patient more comfortable during functional movements.

When compared to a conventional attachment, a semi precision attachment for a cast metal frame removable partial denture can perform a number of functions better. Proper assessment of the condition of the abutment teeth is needed for an adequate indication. Selecting the type of semi precision attachment is primarily determined by the available maxilla-mandibular space, the crown length as well as the possibility of adequate oral self-care. ${ }^{7-9}$

\section{Conclusion}

Although semi precision attachment requires higher cost, additional chair side time to be incorporated in removable partial dentures but it transforms patient attitude to the wearing of removable prosthesis. They are more retentive and stable in the mouth as compared to conventional removable partial dentures and for these reasons are better tolerated.

\section{References}

1. Donovan TE, Cho GC. Esthetic considerations with removable partial dentures. J Calif Dent Assoc 2003; 31(7):551-7.

2. Santana-Penín U, Mora MJ . An esthetically attractivetwinflex clasp for removable partial dentures. J Prosthet Dent 1998; 80(3):367-70.

3. Barry Rubel, Edward E. Hill. Unilateral Semi-Precision Removable Partial Denture utilizing Bredent VKS-SG Attachment System. NYSDJ 2009; 39-8.

4. Den Haan R, Battistuzzi PG, Witter DJ , de Baat C, Creugers $\mathrm{NH}$. Semi-precision attachments for cast metal frame removable partial dentures. Ned Tijdschr Tandheelkd 2011; 118(2):93-100.

5. Beaumont AJ J r. An overview of esthetics with removable partial dentures. Quintessence Int 2002; 33(10):747-55

6. Rodney D. Phonix. Stewarts, Clinical removable partial prosthodontics, Quintessence Publishing. Third edition

7. Khan SB, Geerts GA. Aesthetic clasp design for removable partial dentures: A literature review SADJ 2005; 60(5):1904.

8. DeRossi A, Albuquerque RF J r, Bezzon OL. Esthetic options for the fabrication of removable partial dentures: a clinical report. J Prosthet Dent 2001; 86(5):465-7.

9. Harol W Preiskel. Precision attachment in Prosthodontics, Chicago: Quintessence Publishing Co. Inc. 1984.

\section{Gain quick access to our journal online View our journal at www.nacd.in}

